\title{
AN UNUSUAL NEST OF POGONOMYRMEX ${ }^{1}$
}

\author{
By GeORge S. TUlLOCH
}

During 1919 Professor Harlow Shapley, while collecting in the vicinity of Pasadena, California, discovered a nest of Pogonomyrmex californicus Buckley in which a large number of the worker-like forms possessed vestiges of wings. Professor Shapley noted this unusual occurrence of workers possessing vestigial wings $(1920,1921)$ and considered them to be pterergates following the term suggested by Dr. Wheeler (1903). Of 1737 worker-like forms taken from this nest during 1919 and 1920, 740 were found to possess vestigial anterior wings or the stubs of broken fore wings. Four ants were noted which possessed vestiges of both fore and hind wings- "a phenomenon not heretofore recorded, as only anterior wings are represented in all other pterergates." There appeared to be no obvious reason why this particular nest should present such an anomalous condition as the intermittent war with the Argentine ant (Iridomyrmex humilis Mayr) which has been introduced there, was no more severe for these ants than those of neighboring colonies of the same species. It was noted, however, that this nest had little access to wild barley and similar grasses which is a common food of the species, yet it was well provisioned with mixed grains from a nearby feed store whenever the Argentine ants permitted the nest to be opened for normal harvesting activities. An examination of several thousand individuals from fifty colonies within a radius of two miles yielded only one pterergate.

While engaged in a study of the Formicoid thorax, Dr. Wheeler suggested that the writer communicate with Professor Shapley and ask permission to examine specimens

${ }^{1}$ Contribution from the Entomological Laboratory of the Bussey Institution, Harvard University, No. 328. 
from this interesting nest. Professor Shapley kindly gave the writer specimens of the different forms and in conversation described the region in which the nest was found. The writer wishes to thank Professor Shapley for these abnormal specimens and for numerous facts concerning these ants in the locality of Pasadena, California. To Dr. Wheeler the writer wishes to express his thanks for his opinions concerning the specimens.

According to Creighton (1928) abnormalities in ants appear to fall into three fairly well defined categories :

1. Sex mosaics and intersexes. ${ }^{2}$

2. Aberrant forms produced through altered food supply.

3. Freaks and atavistic forms.

The first group includes the various lateral mosaics as well as the rarer antero-posterior type. The second group includes a large number of peculiar forms which arise from pronounced nutritional irregularities. Lack of food may produce dwarf individuals, while loss of food due to the presence of parasites gives rise to pseudogynes. In the event of an overabundance of food, unusually large males and females, egg-laying workers and, more rarely, repletes may result. In the third group may be included those individuals which show duplication, loss or malformation of parts and atavistic forms.

The method by which aberrant forms, particularly pseudogynes, may be produced through altered food supply has been studied by Wasman for more than thirty years. He has suggested the following hypotheses.

1. Ants of colonies, having their larval broods devoured by the Lomechusa larvæ try to transmute into workers some larvæ which have already developed somewhat along the path terminating in the queen phase. These efforts result in the production of forms that belong to neither caste.

\footnotetext{
${ }^{2}$ Intersexes should probably fall in the second category, as recent works indicate that they are produced through a change in the rate of metabolism.
} 
2. Pseudogynes may arise without any effort at transmutation but from female larvæ that have been merely neglected and left unfed after they have passed the stage at which such treatment would lead to the formation of workers. "That the pseudogynes are not the result of pathogenic conditions in the egg or mother queen has been proved experimentally by Viehmeyer (1904) who removed an aged sanguinea queen from a colony that for years had been producing pseudogynes, owing to the presence of Lomechusa larvæ and caused her to be adopted by a new set of unusually healthy workers from an uninfested colony. Under the changed conditions her eggs developed into larvæ that gave rise to perfectly normal workers" (Wheeler, 1910). It would appear, therefore, that pseudogynes result from an upset in the nutritional balance due to the presence of parasites, although it is impossible to state positively whether they are transmuted females or over-developed workers.

The pterergate falls into the third group of abnormal ants, i. e. freaks and atavistic forms. As there are only a few cases of such forms on record (nine prior to 1920) their sporadic appearance would indicate that they are extremely unusual and thus may be classified in the third category. Dewitz (1878) has shown that in Formica the embryonic vestiges of wings are retained until the larval and pupal stages, and it is not surprising, therefore, that we should occasionally find some workers which retain them until the adult stage. No doubt this phenomenon occurs more often than has been suspected, and the minute vestiges are broken off during emergence from the pupal case, or during the mutual stroking of their bodies with their antennæ, to which the ants devote so much of their time. Since the retention of a character that usually disappears among the normal forms is in the broad sense of the term a freak, pterergates or workers possessing vestiges of wings, though in other characteristics exactly like the true worker, fall readily into the third group of abnormal ants suggested by Creighton.

The difference between pseudogynes and workers is very distinct when a large series of forms is available for study, and many comparisons may be made between them. The 
pseudogyne is characterized by an enlarged mesonotum and oftentimes by the presence of vestigial wings. It is more robust than the worker, and in the case of some forms retains the median ocellus which entirely disappears in the worker. However, a very complete series of intergrades may be noted, and in some cases a pseudogyne so nearly approximates a worker in size and in shape that a careful examination is necessary to differentiate between them. Pterergates and pseudogynes are easily distinguishable. In the case of a wingless pseudogyne and a pterergate, the distinction is obvious. In the case of a winged pseudogyne and a pterergate, the difference is one of size and structure of the thorax. Usually in winged pseudogynes the lower intergrades tend to lose their wings as they become reduced in size, so that the less developed individuals differ only in size from the worker and from the pterergates both in size and the absence of wings.

From the foregoing discussion of the polymorphic forms of the female ant, it may be noted that the distinctions between the forms are based mainly upon thoracic characters. The thorax of the female ants is as specialized as any that may be found among the winged insects, while the thorax of the worker ants is the most highly specialized, and at the same time as simplified as may be found among all insects. Adlerz has stated in his Myrmecologiska Studier that "we know that those characteristics that distinguish the typical worker from the queen are partly of a retrogressive nature; for example, the reduction of the receptaculum seminis, ovaries, eyes, wings, together with their muscles and muscular attachments, and partly progressive, for example, the increased size of mandibles and their muscles." The adoption of a terrestrial habit and the subsequent disappearance of wings has resulted in a fusion of sclerites in the thoracic region which makes a homological study almost impossible. Usually the dimorphic forms, the winged sexual forms and the wingless workers, are the only forms available for study, the intermediate forms having disappeared during phylogeny. Occasionally intermediate forms appear, giving convenient graduations from the winged to the wingless state, showing how the fusion of the sclerites and the simplification of the thorax may have taken place. In the 
material received from Professor Shapley a very interesting series of pseudogynes was noted. ${ }^{3}$ Since this series may be of significance in tracing the evolution of the wingless worker from the winged form, this description is offered.

The typical female of $P$. californicus Buckley is rather a large form (Fig. 1, A) about $8-9 \mathrm{~mm}$. in length. It is much larger than the workers and pseudogynes, the difference in size being most noticeable in the thorax and gaster. The thorax is of the typical Myrmicine type, being characterized by the presence of a large parascutellar region on either side of the mesonotum and by the absence of a distinct metathoracic spiracle. In the mesonotum the prescutum is fused with the scutum. The notauli are absent and the parapsidal furrows extend but a short distance forward from the transcutual suture. The lateral and sternal sclerites of the mesothorax are fused and modified so as to make their identification rather difficult. In the mesopleuron the epimeron persists as a narrow region bordering the postero-dorsal margin of the episternum. The episternum is secondly divided into an upper (anepisternum) and lower (katepisternum) plate. The metanotum is reduced to a transverse plate and the metapleuron is almost indistinguishably fused with the propodeum.

The modifications noted in the series selected for study are as follows. Fig. B is a lateral view of one of the larger winged pseudogynes. In this form fusion of the sclerites in the notal region has taken place although the mesonotal region is still enlarged, while the mesopleural region is practically unchanged except for a reduction in size. Vestigial wings and poorly developed tegulæ are present. The metanotum persists as a transverse plate almost indistinguishably fused with the mesonotum and propodeum. In the form next to the true worker (Fig. C) fusion of the pleural region as well as the notal region has taken place, yet the pronotum is still separated from the enlarged mesonotum, the promesontal suture persisting in its entirety. In pseudogynes similar to this one vestigial

\footnotetext{
${ }^{3}$ Shapley considered these forms to be pterergates, but a comparison of a large number with the typical worker shows them to be pseudogynes.
} 
wings were noted (textfigure). The thorax of the true worker (Fig. C) is one of the most specialized found among the ants. The mesonotum is reduced in size and the sclerites
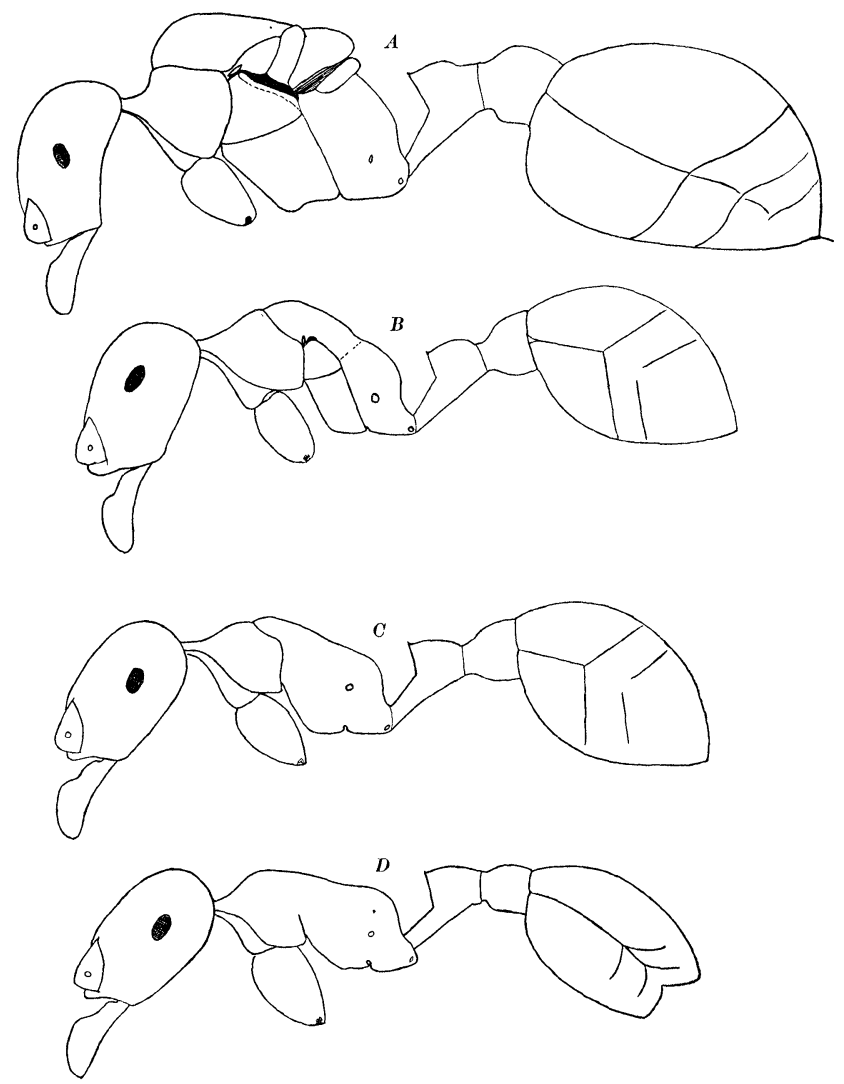

Fig. 1. A, Queen of $P$. californicus with wings removed; $B$ and $C$, pseudogynes of $P$. californicus; $D$, worker of $P$. californicus.

have fused together, except the lateral region of the pronotum with the mesopleuron.

In order to comprehend the significance of this series, it is necessary to consider the manner in which a wing 
bearing segment may have been evolved from a wingless segment. Snodgrass (1926) has suggested that the insect's ancestor may have been a soft-bodied, segmented animal, resembling in its segmentation the soft-bodied larvæ of some modern insects. Modern adult arthropods, unlike their hypothetical ancestors, have the thorax modified as the locomotor region of the body, and are in general hardshelled forms, having developed an external skeleton formed of calcareous or chitinous matter, and the hardening of the body wall has had a profound influence on the structure of the segments and on the general mechanism of the animal. The skeletal deposits have taken the form of segmental plates, of which the principal is a dorsal, or tergum and a ventral, or sternum. These two plates are separated on the sides of the segment by a membranous pleural area. The condition found in a wingless thoracic segment is fundamentally of this structure, except that a chitinous pleural plate is present and connected to the tergum and sternum by membranous regions. In the winged thoracic segment these plates have become modified to strengthen the thorax in order to provide solid attachment points for the muscles of the wings. This has come about by the formation of chitinous antecoxal and postcoxal bridges connecting the pleuron and sternum, as well as prealar and postalar bridges connecting the pleuron and tergum. The tergum has become secondarily divided to provide muscle attachment points. Thus the transition from the wingless thoracic segment to the winged segment has been one of strengthening the thorax to accommodate the muscle stresses concomitant with the acquisition of wings.

The embryonic history of insects substantiates the fact that the thorax was first differentiated as the locomotor region of the body by a specialization of three pairs of segmented appendages as the principal organs of progression, this being accomplished by the modification of the gnathal appendages to feeding organs and by the suppression of most of the abdominal appendages. Flight being a comparatively recent development as a further mode of progression, the development of wings and the perfection of the mechanism meant a further and much greater alternation in the structure of the wing-bearing segment than 
that which was evolved to accommodate the legs. With a return to a terrestrial environment it is natural to expect that the character most recently acquired should be the first to disappear. In the series of intermediate forms of Pogonomyrmex from queen to worker this is precisely what has happened. The appearance of functionless wings, the reduction in the size of the thorax due to the reduction in size of the wing muscles, and the simplification of the mesonotal region presents a stage in the evolution of the apterous forms from the winged forms. This progressive reduction in size of the thorax and wings, and the simplification of the pleural as well as the notal regions represents a recessive stage in the evolutionary series. The loss of vestigial wings and a progressive reduction in size represents a further step, and the true worker type marks the culmination of a long series of evolutionary stages from the winged to the apterous condition. Usually the intermediate forms have disappeared, and only the first and final stages are present, but occasionally abnormal forms such as these persist and give us a convenient series of connecting forms. Moreover, one is not compelled to formulate any hypotheses or construct any hypothetical figures as has been done in the case of the evolutionary stages from the wingless ancestors to the winged insects; here we have living examples of the connecting stages, a condition which is not usually met with in evolutionary study. The writer is very fortunate in having at his disposal these connecting links in most of the subfamilies of the ants. These series will be considered in a later and more comprehensive paper.

The wings of the queen and winged pseudogynes are illustrated in the textfigure. The wing of the queen is about $6 \mathrm{~mm}$. in length and is much reduced in the distal region (Fig. a). The venation of the wing of the first pseudogyne is much reduced, especially in the anal and cubital region. The vestiges in forms similar to Fig. C consist of a small veinless wing sac. The grouping of the winged intermediate forms roughly in order of the development of vestiges by Shapley follows:

With minute veinless wing-sacs, or with stubs of broken wings-385. 
With sacs from 0.5 to 1.0 long and indistinct veining219.

With transparent, clearly veined winglets from 0.8-1.5 -132 .

He further states that "the gradation of wing vestiges is, however, perfectly continuous, from small protuberances (without appendages) on the mesothoracic segment to the most developed winglets, with venation approaching that

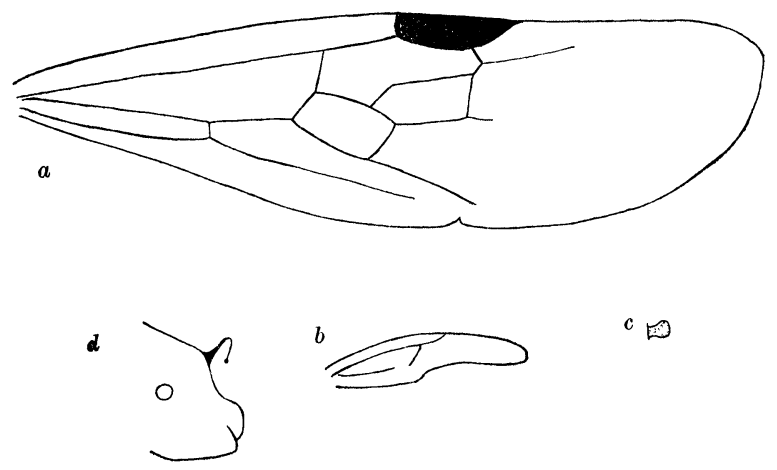

Fig. 2. a, wing of queen of Pogonomyrmex californicus, Buckley; $b$, wing of pseudogyne shown in Fig. $1, \mathrm{~B}$; $c$, wing of pseudogyne shown in Fig. 1, C; $d$, propodeum of pseudogyne.

of the wing (6 $\mathrm{mm}$. in length) of the mature queen." Brues (1903) distinguishes three types of vestigial wings:

1. Wings having essentially a pupal character, viz, developing as normal wings up to the pupal stage, but failing to expand.

2. Wings essentially normal except for their similar size and less complex venation.

3. Wings consisting of little more than a hollow bag and giving no clue from their appearance as to the probable wing structure of their ancestors.

The vestigial wing (Fig. b) from the first pseudogyne of the series would fall into the second category, while the 
sac-like vestige (Fig. c) of a wing from forms similar to Fig. c would fall into the third group. The third group apparently represents the stage just preceding total aptery and is, therefore, phylogenetically, the most recent condition.

In addition to the pseudogynes found in this nest another interesting group of four specimens was noted. These were supposedly workers possessing vestiges of both fore and hind wings. On examining a specimen of this form the writer finds it to be a deälated female, the stubs of wings giving the impression of vestigial wings. However, this particular specimen is extremely interesting from another point of view, as it possesses a propodeal spine on the right side of the body and none on the left. (Fig. d) Since spines do not occur on this particular species this specimen may be classified as a freak, since it is probably an atavistic form.

\section{Literature Cited}

Brues, C. T. 1903. The Structure and Significance of Vestigial Wings Among Insects. Biol. Bull. Vol. IV, No. 4.

Creighton, W. S. 1928. Notes on Three Abnormal Ants. Psyche, Vol. XXXV, No. 1.

Dewitz. 1878. Beiträge zur postembryonalen Gliedmassenbildung bei den Insecten. Zeitsch. f. wiss. Zool., XXX, Suppl. pp. 78-105, Taf. V.

Shapley, Harlow. 1920. Notes on Pterergates in the Californian Harvester Ant. Psyche, XXVII, No. 4. 1921. Preliminary Report on Pterergates in Pogonomyrmex californicus. Proc. Nat. Acad. Sci., Vol. 6, No. 12, pp. 687-690.

Snodgrass, R. E. 1926. Morphology and Mechanism of the Insect Thorax. Smithsonian Publication, No. 2915.

Wheeler, W. M. 1903. Worker Ants with Vestiges of Wings. Bull. Amer. Mus. of Nat. Hist. Vol. XXI, Art. 24, pp. 405-408. 

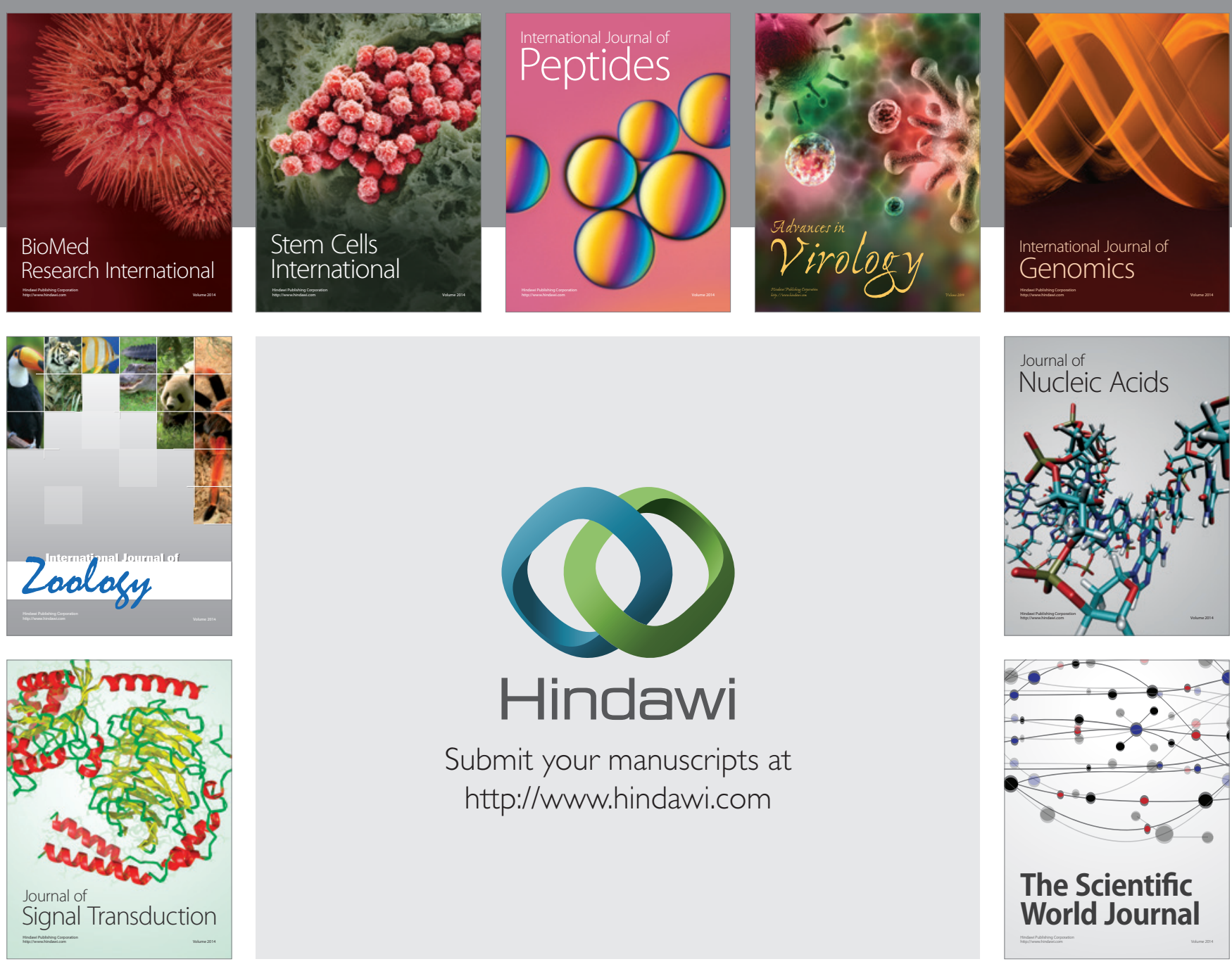

Submit your manuscripts at

http://www.hindawi.com
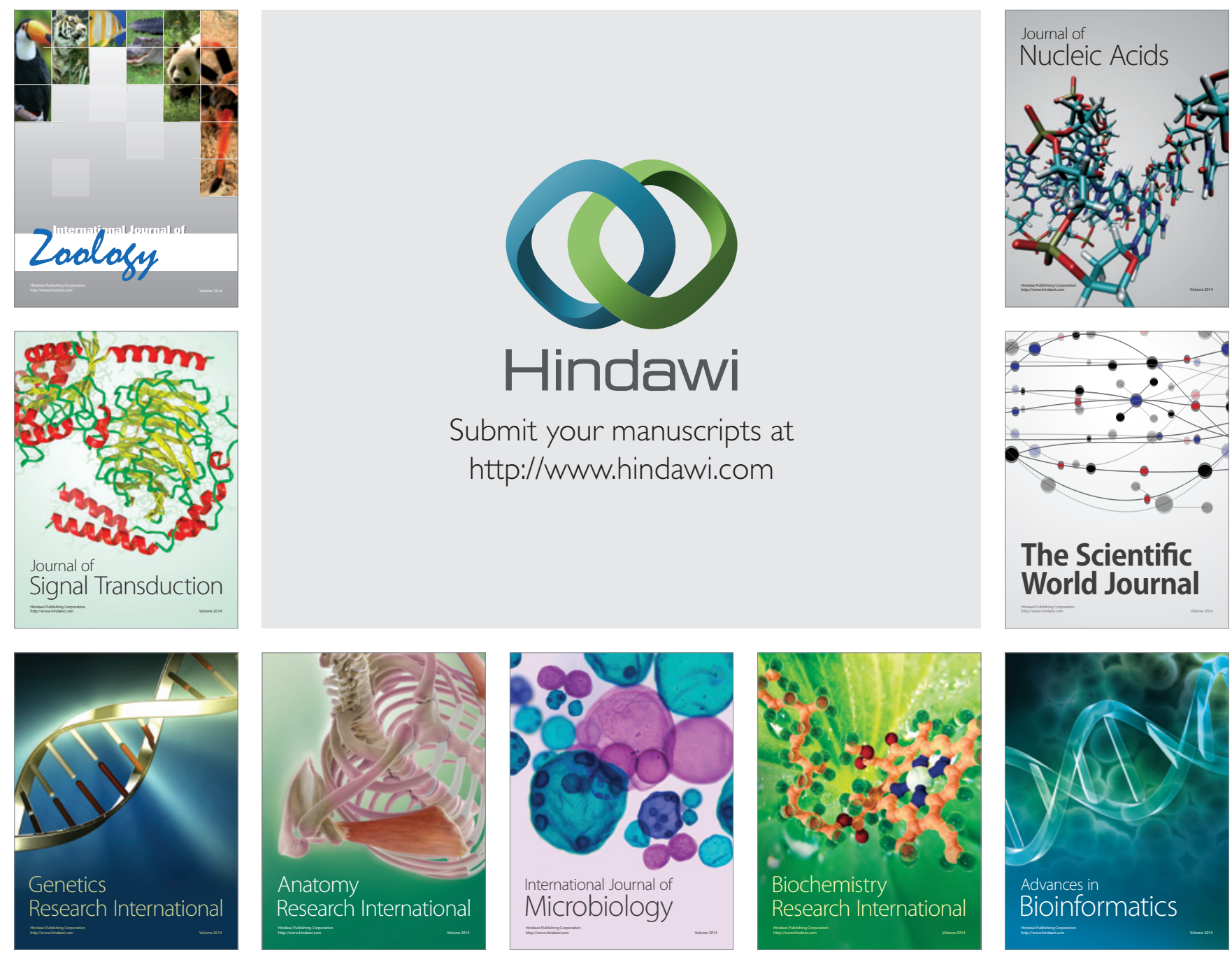

The Scientific World Journal
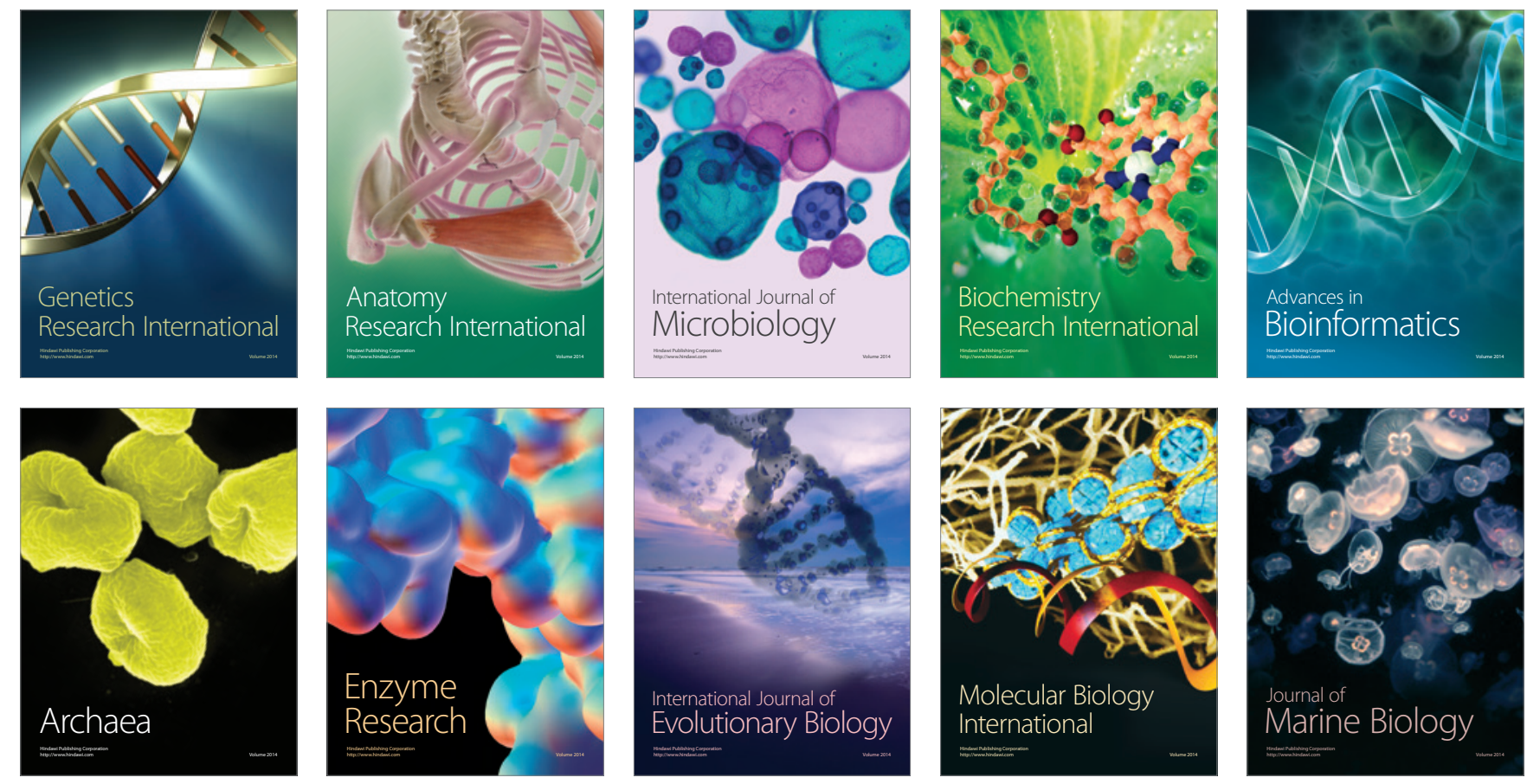